\title{
Attitudes of Special Education Teachers in Jordanian Private Schools towards the Inclusion of Autistic Children in These Schools: Empirical Study
}

\author{
Wesam Hani Saleh Nawafleh \\ Jordan
}

\begin{abstract}
The present study aimed to explore the attitudes of special education teachers in Jordanian private schools towards the inclusion of autistic children in these schools. The researcher adopted a descriptive analytical approach. He selected a random sample that consists from 70 female and male special education teachers. Those teachers were selected from 14 private schools located in Amman, Jordan. Questionnaire forms were distributed to those teachers by hand. All the distributed forms were retrieved and deemed valid for analysis. To analyse data, the SPSS software and descriptive statistical methods were used. Several results were reached. For instance, special education teachers in Jordanian private schools have negative attitudes towards the inclusion of autistic children in these schools. In addition, such inclusion shall not encourage autistic children to engage in group games with their normal peers. It shall not improve the social, academic and adaptive skills of those students nor their capability to face challenges independently. Jordanian private schools have many resources and adequate funds for supporting such inclusion.
\end{abstract}

Keywords: Attitudes, special education, inclusion, autism, private schools, Jordan

DOI: $10.7176 / \mathrm{JEP} / 11-27-07$

Publication date:September $30^{\text {th }} 2020$

\section{Introduction}

During the last decade, the number of autistic individuals has been increasing (Kuzminski et al., 2019). Hence, there is a need to conduct studies about autistic individuals and autism. Autism (i.e. autism spectrum disorder (ASD)) refers to a neurodevelopmental condition which is associated with communication \& social deficits, and repetitive and restricted activities, behaviours \& interests. The intellectual disability and language disorders are common among autistic individuals. The autistic individuals may be learning slowly and suffer from difficulties in comprehending and producing language. Autistic individuals suffer from poor capabilities in understanding language functions (i.e. irony). They show failure in using expressive gestures and following the eye gaze of someone. They may learn few functional gestures. They suffer from impaired joint attention. They have difficulties in establishing, maintaining and understanding relationships, including: relationship with colleagues, co-workers, siblings and care givers (The American Psychiatric Association, 2013).

Autistic individuals have poor imagination and poor capability to engage in group games. They have poor capability to comply with the rules of games. They have difficulties in understanding what behaviour is considered appropriate. They have poor adaptive skills. Disruptive and challenging behaviour are common among autistic individuals. They show lack of interest in social interaction, especially during the early years of life. Many autistic individuals can learn the way of supressing repetitive behaviours in public (The American Psychiatric Association, 2013).

Only minority of autistic adults are capable of working and living independently. Despite that, those adults are vulnerable, \& socially naïve and suffer from difficulties in meeting practical demands without aid. They are prone to depression and anxiety (The American Psychiatric Association, 2013). Autistic individuals suffer from social isolation, because they have difficulties in interacting socially with others and making friendships. They are less invited to engage in social activities and events. They suffer from poor interpersonal communication skills. They are treated differently than their normal peers. Hence, the life quality of autistic individuals is usually low (Kuzminski et al., 2019).

In order to make autistic children feel like their normal peers, they must be provided with opportunities to get enrolled in schools, higher education institution and job opportunities like their normal peers (Kuzminski et al., 2019). Some autistic individuals deserve getting more opportunities, because they have exceptional abilities in a specific area (e.g. art, IT, or etc..). However, media transmits false information about autistic individual. Such false information negatively affects people's attitudes towards autistic individuals. It leads to promoting misconceptions about autistic children. It hinders autistic individuals from receiving opportunities in a manner that is equal to their peers (Huws and Jones, 2010).

To ensure that disabled and normal students are provided with equal educational opportunities, the term (inclusion) emerged. Inclusion refers to the integration of disabled children in the general education classroom. It also involves the integration of disabled students in the activities or games carried out in the general education 
classroom to interact with their normal peers (Thomson, 2002; Abdel Fattah, 2018). During the last couple of decades, several governments -e.g. the United States of America- started integrating disabled students -including autistic students- in general education classrooms. In fact, several governments enacted legislations to ensure that disabled students -including autistic students- are provided with the opportunity to learn in general education classrooms. That is because learning with their normal peers is considered a right for all disabled students. It's because the exclusion of disabled students from general education classrooms means that that disabled and normal students aren't provided with equal educational opportunities (Merry, 2020).

Today, many countries- the United States- have been provided disabled students with individualized education programs. Such programs are based on the educational needs of each student. In such programs, the inclusion of disabled students in the general educational classrooms is maximized as much as possible (Merry, 2020). It should be noted that the inclusion of autistic children is a right and a need. That is because autistic children are in need for being cared for and understood. It's because autistic children are in need for establishing social relationships with their normal peers. Despite that, there are many countries that refrain from integrating autistic children in general education classrooms (Merry, 2020). For instance, in Jordan, autistic children receive education in special educational centres (Theeb, and Muhaidat, 2013).

Although the inclusion of autistic children is important, there are several requirements that must be met for having an effective inclusion. For instance, the inclusive schools must provide training for all the members of the staff (i.e. special education teachers, paraprofessionals, regular education teachers, receptionists, administrators, parents, and food service workers) (Crisman, 2009). Teachers in such schools must dedicate much time for identifying and meeting the needs of autistic children. They must show patience for identifying and meeting such needs (Merry, 2020). Schools must have good sources of funding and provide the needed resources for supporting the inclusion of autistic children (Roberts, and Simpson, 2016).

It is suggested that teachers' attitudes and enthusiasm affect the expectations, academic achievement and selfimage of autistic students (Natof \& Romanczyk, 2009). Hence, exploring teachers' attitudes shall contribute to the improvement of the quality of the school education provided for autistic students. Therefore, the researcher of the present study aimed to explore the attitudes of special education teachers in Jordanian private schools towards the inclusion of autistic children in these schools.

\section{Objective:}

The present study aimed to explore the attitudes of special education teachers in Jordanian private schools towards the inclusion of autistic children in these schools

\section{Question:}

The researcher aimed to answer the following question:

What are the attitudes of special education teachers in Jordanian private schools towards the inclusion of autistic children in these schools?

\section{The Study's Significance:}

The present study is significant because it fills a gap in the relevant literature. As far as the researcher knows, there isn't any study that aims at exploring the attitudes of special education teachers in Jordanian private schools towards the inclusion of autistic children in these schools. The present study is significant because it provides beneficial information for:

-Officials at the Jordanian Ministry of Education: This study provides those official with knowledge about the willingness of special education teachers to integrate autistic children in schools. This knowledge enables officials to make decisions in this regard that are for the favour of autistic children.

-Parents of autistic children in Jordan: This study provides those parents with knowledge about the willingness of special education teachers to integrate their autistic children in private schools.

\section{The Study's Limits:}

Temporal limits: This study was conducted during the first semester of the academic year (2019/2020).

Spatial limits: This study was conducted in several private schools in Amman, Jordan

Human limits: The researcher surveyed several special education teachers who work in private schools in Amman, Jordan.

\section{Definition of Terms}

\subsection{Theoretical definitions}

-Attitude: It refers to an evaluative judgment. This judgment represents the extent to which someone likes or dislikes a thing or a person (Crano and Prislin, 2006, p.347).

-Inclusion: It refers to the integration of disabled children in the general education classroom. It also involves 
the integration of disabled students in the activities or games carried out in the general education classrooms to interact with their normal peers (Thomson, 2002; Abdel Fattah, 2018).

-Autism: It is a neurodevelopmental condition which is associated with communication and social deficits, and repetitive and restricted activities, behaviours and interests. The intellectual disability and language disorders are common among autistic individuals (American Psychiatric Association, 2013).

\subsection{Operational definitions}

-Attitudes: They refer to the attitudes of special education teachers in Jordanian private schools towards the inclusion of autistic children in these schools.

-Inclusion: It refers to the integration of autistic children in the general education classrooms in Jordanian private schools.

-Autistic children: They refer to the children who were diagnosed with autism and enrolled in special educational centres for autistic children in Jordan.

\section{Theoretical Framework:}

The inclusion of autistic children requires having good relationships between the general education teachers and autistic children. In fact, having such relationships shall reduce the frequency of the behavioural problems made by autistic children in classroom. It shall increase the social engagement of those children in classroom activities (Robertson, 2003). The inclusion of autistic children is difficult, because those children suffer from poor skills and behavioural problems. Such inclusion is difficult because the curricula must be adjusted and special training must be provided to general education teachers (Cassady, 2011).

To ensure that the inclusion programs of autistic children are effective, there must be adequate number of support staff per student in school. Having support and assistant teachers shall reduce the emotional and behavioural problems of autistic children. They play a significant role in improving pro-social behaviour of autistic students. Providing autistic children in inclusive classes with trained teachers shall promote a sense of belonging to school (Osborne \& Reed, 2011).

Inclusion of autistic children requires providing normal children with knowledge about the strategies to be used for teaching autistic children and interacting with them. It must be partial inclusion, because autistic children must be provided with special education and care. It should be implemented in the general education classrooms that include a high number of normal students to provide autistic children with many opportunism to interact socially with their normal peers. It should be implemented in the schools that adopt effective management styles that allow the parents of autistic children to identify the activities carried out in each school day (Gavalda and Qinyi, 2012)

The inclusion programs of autistic children must meet several requirements. For instance, they must involve the parents of autistic children are highly involved in such programs. They must provide emotional support to parents and engage them in the training courses and workshop to enrich their knowledge on autism and inclusive education. They must be implemented starting from an early stage of childhood. They must be implemented in an intensive manner. They must provide teachers with specialized professional training. They must carry out regular assessment for the progress of the disabled students. They must include plans for covering the material in the targeted curricula. They should promote collaboration between healthcare professionals and the educators of autistic children. They should ensure that educators keep up with the latest knowledge on the way autistic children learn and adapt socially (Gavalda and Qinyi, 2012).

It should be noted that there are many challenges associated with the inclusion of autistic children. Such challenges include: loneliness, bullying and difficulties in establishing social relationship with normal peers. They include: the lack of knowledge among students and general education teachers about autism. Such lack of knowledge increases the severity of the problems associated with the inclusion of those children (Hebron, and Humphrey, 2014). The inclusion of autistic children shall probably make those children experience much anxiety and depression. It shall probably make those children feel socially excluded and alienated (Goodall, 2018).

\section{Empirical Literature:}

Al-Smadi (2010) aimed to explore the attitudes of teachers towards the inclusion of disabled students in the first three grades in Ar'ar, Saudi Arabia. A stratified purposive sample was selected. It consists from 142 teachers. A questionnaire was used for collecting data. It sheds a light on three areas; social, psychological and academic areas. It was found that respondents have positive attitudes. In terms of the social area, inclusion provides disabled students with better social interaction opportunities and improve disabled students' self-efficacy. It develops disabled students' social skills. Teachers believe that disabled students feel shy in inclusive classrooms. In terms of the academic area, inclusion programs offer effective solutions for addressing the academic problems of disabled students. They develop disabled students' academic skills. In terms of the psychological area, inclusions 
increases disabled students' self-satisfaction and confidence levels. It makes those students feel productive. It improves disabled students' social adaptive skills. It improves their capabilities to face challenges independently.

Lindsay et al. (2013) aimed to explore the challenges associated with integrating autistic children in general education classrooms in two cities located in Ontario, Canada. Data was collected through making in-depth interviews with thirteen teachers who teach autistic students in general education classrooms. Those teachers were selected through the purposive sampling method. It was found that such challenges include: difficulties in understanding and managing those children's behaviours in classroom, poor school policies, lack of resources at school, and providing teachers with insufficient training. In addition, the teachers, parents and student aren't cooperative in this regard.

Al-Suwaiti (2016) aimed to explore the attitudes of administrators and teachers in general education classrooms towards the inclusion of disabled children in primary schools in in Al-Khaleel, Palestine. He aimed to explore the challenges associated with such inclusion. The sample consists from 110 administrators and teachers. The random stratified sampling method was used. A questionnaire was used for collecting data. The SPSS program was used. Several results were reached. For instance, the sampled administrators and teachers have positive attitudes towards such inclusion. Such inclusion provides disabled studies with better social interaction opportunities. Such opportunities shall enable disabled children to adjust socially in society. Such inclusion promotes acceptance for the ones who are different. It negatively affects the affective development of disabled children. It negatively affects the quality of the education provided to normal children, because disabled children shall consume much time in class. The challenges associated with such inclusion include: the lack of medical services in schools. They include: the lack of the training courses provided for special education teachers about the way of dealing with disabled children in inclusive classrooms. They include: the rejection of the normal children's parents for inclusive education. They include: the lack of the resources and educational means needed by disabled students at school.

Abdel Fattah (2018) aimed to explore teachers' attitudes towards the inclusion of disabled students in the public schools located in Salfit, Palestine. A descriptive analytical approach was adopted. A random stratified sample was selected. It consists from 200 teachers. A forty-five item questionnaire was used for collecting data. It sheds a light on three areas. These areas are: 1)- teachers' training and expertise. 2)- attitudes towards the conditions of the environment. 3)- attitudes towards social and psychological aspects related to dealing with the disabled students and their children. It was found that teachers have positive attitudes towards the aforementioned inclusion. Teacher received much training about inclusion. They possess much expertise in this regard. The Palestinian Ministry of Education contributes to the promotion of inclusion. In terms of the conditions of the environment, the targeted schools have a plan for implementing such inclusion. The educational leaders in the targeted schools monitor the way of treating disabled students. The curricula and the classroom environment in the targeted schools are not suitable for implementing such inclusion. The resources (e.g. special games), structure and the facilities of the targeted schools aren't not suitable for implementing such inclusion. Teachers aren't asked to submit regular progress report about disabled students. In terms of the social and psychological aspects, teachers seek improving the psychological wellbeing of disabled students in school. They empathize with parents of disabled students because those parents usually suffer from stress. In addition, teachers communicate with disabled students after school to explore their behaviours.

\section{Methodology:}

\subsection{Approach}

The researcher adopted a descriptive analytical approach

\subsection{Population and Sample}

The population is represented in all the special educational teachers who work in private schools in Jordan. The researcher selected a random sample that consists from 70 female and male special education teachers. Those teachers were selected from 14 private schools located in Amman, Jordan. All the selected schools are inclusive schools. Questionnaire forms were distributed to those teachers by hand. All the forms were retrieved and deemed valid for analysis. The response rate is one hundred percent. Information about the sample are presented through the table shown below: 
Table (1): Distribution of the respondents in accordance with gender and academic qualification

\begin{tabular}{|l|l|l|l|}
\hline Variable & Category & Frequency & Percentage \\
\hline \multirow{3}{*}{ Gender } & Female & 54 & 77.142 \\
\cline { 2 - 4 } & Male & 16 & 22.857 \\
\hline \multirow{5}{*}{ Academic qualification } & BA degree & 56 & 80 \\
\cline { 2 - 4 } & MA degree & 8 & 11.428 \\
\cline { 2 - 4 } & Higher Diploma & 6 & 8.571 \\
\cline { 2 - 4 } & PhD degree & 0 & 0 \\
\hline
\end{tabular}

$\mathrm{N}=70$

$77.14 \%$ of the respondents are females and $22.857 \%$ of the respondents are males. In addition, $80 \%$ of the respondents hold BA degree only. $11.428 \%$ of the respondents hold MA degree and $8.571 \%$ of the respondents hold higher diploma. None of the respondents hold a PhD degree. That indicates that private school don't recruit specialists who hold $\mathrm{PhD}$ in special education. However, awareness must be promoted among leaders in private schools about the significance of recruiting specialists who hold $\mathrm{PhD}$ in special education.

\subsection{Instrument}

The researcher developed a five point Likert questionnaire. This questionnaire was developed based on the studies of Al-Smadi (2010), Al-Suwaiti (2016), Abdel Fattah (2018), Lindsay et al. (2013), Huws and Jones (2010), Roberts, and Simpson (2016). It consists from 2 main parts and a cover page. The cover page identifies the name of the researcher and the goal sought from collecting data. It suggests that collected data shall be processed statistically and remain confidential. It suggests that the collected data shall be used only for meeting goal related to the present research. The first part of the questionnaire collects data about gender and academic qualification. The second part of the questionnaire collects data about the respondents' attitudes towards the inclusion of autistic children in Jordanian private schools. The instrument was passed to the members of the sample in Arabic language. It was translated by a specialised translator to be displayed in this study.

\subsection{Validity}

To check the validity of the questionnaire, the researcher passed the initial version of the questionnaire to three experts. The initial version was passed in Arabic language. The latter experts are Jordanian faculty members who are specialised in special education. They were asked to make an assessment for the questionnaire in terms of clarity, language, and relevancy. All the experts suggested that the questionnaire is clear, reliable, relevant to the study's goal and free from language mistakes. However, one faculty member recommended deleting two statement due to irrelevancy. Another faculty member recommended adding a statement. Hence, changes were made and the final version of the questionnaire was drafted.

\subsection{Reliability}

For measuring the reliably of the questionnaire, Cronbach alpha coefficient value was calculated. The latter value is 0.814 . The latter value indicates that the questionnaire is highly reliable and offers reliable results. That is because this value is greater than 0.70 as it's suggested by Salehi \& Farhang (2019).

\subsection{Statistical analysis methods:}

The researcher used descriptive statistics and the SPSS program. For instance, Standard deviations and means were calculated to explore the respondents' attitudes. In addition, percentages and frequencies are calculated to explore the characteristics of the sample. Cronbach alpha coefficient value was calculated for assessing the reliability of the questionnaire.

\subsection{Criteria for classifying means:}

For classifying means, specific criteria were adopted. Such criteria are shown below:

Table (2): The criteria employed to classify means

\begin{tabular}{|l|l|l|}
\hline Range & Level & Attitude \\
\hline 2.33 or less & Low & Negative attitude \\
\hline $2.34-3.66$ & Moderate & Neutral attitude \\
\hline 3.67 or more & High & Positive attitude \\
\hline
\end{tabular}

*Source: Aljbour (2020)

The five point Likert scale involves five (5) categories for rating the answer of each respondent. Those categories are listed below: 
Table (3): The categories of the five point Likert scale

\begin{tabular}{|c|c|}
\hline Category & Score \\
\hline Strongly agree & 5 \\
\hline Agree & 4 \\
\hline Neutral & 3 \\
\hline Disagree & 2 \\
\hline Strongly disagree & 1 \\
\hline
\end{tabular}

*Source: Aljbour (2020)

\section{Discussion and Results}

To explore the attitudes of special education teachers in Jordanian private schools towards the inclusion of autistic children in these schools, means and standard deviations are calculated. They are presented below Table (4): The attitudes of special education teachers in Jordanian private schools towards the inclusion of autistic children in these schools

\begin{tabular}{|l|l|l|l|l|l|}
\hline No. & Statement & Mean & Std. & Level & Attitudes \\
\hline 1. & $\begin{array}{l}\text { Inclusion of autistic children in private schools shall encourage those } \\
\text { children to engage in group games with their normal peers }\end{array}$ & 1.34 & 0.73 & Low & Negative \\
\hline 2. & $\begin{array}{l}\text { Inclusion of autistic children in in private schools shall improve their } \\
\text { social skills }\end{array}$ & 1.16 & 0.15 & Low & Negative \\
\hline 3. & $\begin{array}{l}\text { The information transmitted through media shall facilitate the } \\
\text { inclusion of autistic children in private schools }\end{array}$ & 3.97 & 0.37 & High & Positive \\
\hline 4. & Private schools have the resources needed for such inclusion & 3.92 & 0.26 & High & Positive \\
\hline 5. & $\begin{array}{l}\text { The autistic children's behaviours can be managed in inclusive } \\
\text { classroom }\end{array}$ & 1.54 & 0.10 & Low & Negative \\
\hline 6. & $\begin{array}{l}\text { The school I work at has adequate funds for supporting the inclusion } \\
\text { of autistic children }\end{array}$ & 3.70 & 0.84 & High & Positive \\
\hline 7. & $\begin{array}{l}\text { The curricula are suitable for teaching autistic children in inclusive } \\
\text { classroom }\end{array}$ & 2.16 & 0.68 & Low & Negative \\
\hline 8. & $\begin{array}{l}\text { In the school I work at, there are medical services and professionals } \\
\text { for providing autistic children with medical care when needed }\end{array}$ & 3.85 & 0.92 & High & Positive \\
\hline 9. & $\begin{array}{l}\text { The inclusion of autistic children in private schools shall improve } \\
\text { their academic skills }\end{array}$ & 1.47 & 0.53 & Low & Negative \\
\hline 10. & $\begin{array}{l}\text { The inclusion of autistic children in private schools shall improve } \\
\text { their adaptive skills }\end{array}$ & 1.30 & 0.61 & Low & Negative \\
\hline 11. & $\begin{array}{l}\text { The inclusion of autistic children in private schools shall improve } \\
\text { confidence }\end{array}$ & 1.29 & 0.74 & Low & Negative \\
\hline 12. & $\begin{array}{l}\text { The inclusion of autistic children in private schools shall improve } \\
\text { their capabilities to face challenges independently }\end{array}$ & 1.15 & 0.33 & Low & Negative \\
\hline 13. & $\begin{array}{l}\text { The teaching strategies used in general education classrooms in } \\
\text { private schools are suitable for teaching autistic children }\end{array}$ & 1.45 & 0.70 & Low & Negative \\
\hline 14. & Total & 2.17 & 0.53 & Low & Negative \\
\hline
\end{tabular}

Based on the table above, special education teachers in Jordanian private schools have negative attitudes towards the inclusion of autistic children in these schools. That is because the overall mean is 2.17 which is negative. The overall standard deviation is 0.53 . The latter result may be attributed to the nature of the disorder. For instance, those children suffer from communication and social deficits, and poor interpersonal communication skills. It was found that the inclusion of autistic children shall not encourage them to engage in group games with their normal peers. That is because the relevant mean is 1.34 . The latter result is consistent with what's suggested by The American Psychiatric Association (2013). Hence, teachers must use special games for autistic children in inclusive classroom.

Inclusion of autistic children in Jordanian private schools shall not improve their social skills, because the relevant mean is 1.16. The latter result is inconsistent with the result concluded by Al-Smadi (2010). That is because such inclusion may make those children feel socially isolated and rejected. Such feelings may result from the rejection of normal children to play and interact with them. It was found that the information transmitted through media facilitates the inclusion of autistic children in private schools, because the relevant mean is 2.23 . The latter result is inconsistent with what's suggested by Huws and Jones (2010). The latter result may be attributed to the increasing awareness among journalists about autism.

Jordanian private schools have the resources needed for such inclusion, because the relevant mean is 3.92. The latter result is inconsistent with the result concluded by Al-Suwaiti (2016). That may be attributed to the fact 
that the fees of most private schools in Jordan are high. Hence, high fees shall enable private schools to provide the resources needed by teachers, and students. It was found that the autistic children's behaviours can't be managed in inclusive classroom, because the relevant mean is 1.54 . The latter result is consistent with the result concluded by Lindsay et al. (2013). It may be attributed to the nature of this disorder. It may be attributed to the fact that controlling autistic children's behaviours inside inclusive classroom shall consume the time dedicated for giving the lesson. It may be attributed to the fact that controlling such behaviours shall hinder teachers from managing the classroom effectively and focus on the content of the lesson.

Jordanian private schools have adequate funds for the inclusion of autistic children, because the relevant mean is 3.70. The latter result is attributed to the fact that the fees of most private schools in Jordan are high. It is attributed to the fact that private schools have several sources of funding, such as: organizing school trips, selling curricula, and providing transportation services etc.. It was found that the curricula aren't suitable for teaching autistic children in inclusive classroom, because the relevant mean is 2.16. The latter result is consistent with the result concluded by Abdel Fattah (2018). It may be attributed to the fact that some autistic children suffer from intellectual disability which hinders them from understanding the content of the curricula used for teaching their normal peers.

It was found that Jordanian private schools have medical services and professionals for providing autistic children with medical care when needed, because the relevant mean is 3.85 . The latter result is consistent with the result concluded by Al-Suwaiti (2016). It may be attributed to the fact that many private schools have nurses and doctors and provide training for their staff about first aid. It was found that the inclusion of autistic children in private schools shall not improve their academic skills, because the relevant mean is 1.47 . The latter result is inconsistent with the result concluded by Al-Smadi (2010). It may be attributed to the fact that the learning needs of autistic children differ from the learning needs of their normal peers. Hence, autistic children are in need for receiving special education.

Inclusion of autistic children in private schools shall not improve their adaptive skills, because the relevant mean is 1.30. The latter result is inconsistent with the result concluded by Al-Smadi (2010). It may be attributed to the fact that autistic children suffer from occupational and social impairments and difficulties in interacting social with others and making friendships. Inclusion of autistic children in private schools shall not improve their confidence, because the relevant mean is 1.29 . The latter result is inconsistent with the result concluded by AlSmadi (2010). It may be attributed to the autistic children shall suffer from social and academic problems in inclusive classrooms. Such problems shall make them feel different and reduce their confidence. Inclusion of autistic children in private schools shall not improve their capabilities to face challenges independently. That's because the relevant mean is 1.15 .

Inclusion of autistic children in private schools shall not improve their capabilities to face challenges independently, because the relevant mean is 1.15 . The latter result is inconsistent with the result concluded by AlSmadi (2010). It may be attributed to the fact that autistic children suffer from major problems in doing things independently. Inclusion of autistic children in private schools shall not improve. It was found that the teaching strategies used in general education in private schools are not suitable for teaching autistic children, because the relevant mean is 1.45 . The latter result is attributed to the fact that autistic children suffer from problems -e.g. joint attention problems- which require using special teaching strategies.

\section{Conclusion}

It was found that special education teachers in Jordanian private schools have negative attitudes towards the inclusion of autistic children in these schools. For instance, such inclusion shall not encourage those children to engage in group games with their normal peers nor improve their social skills. That is because those children suffer from social and communication deficits. It was found that the autistic children's behaviours can't be managed in inclusive classroom, because the disruptive and challenging behaviour are common among those children. Such inclusion shall negatively affect the academic skills of autistic children. That is because those children have special learning needs that differ from the counterpart needs of normal children. Hence, they must be provided with special education. In addition, special teaching strategies must be used for teaching those children.

It was found that the information transmitted through media facilitates the inclusion of autistic children in private schools. That indicates that awareness about autism has been increasing worldwide among journalists. In addition, it was found that Jordanian private schools provide suitable environment for such inclusion. For instance, they have many resources and adequate funds for supporting such inclusion.

\section{Recommendations:}

The researcher recommends the following:

1) Establishing public centres for autistic children in Jordan for providing free educational services to those children

2) Conducting studies that aim at exploring the attitudes of parents, and school leaders towards the 
inclusion of autistic children in Jordanian public and private schools.

3) Conducting similar studies with exploring the impact of special education teachers' demographic variables (e.g. academic qualification and experience) on their attitudes towards the inclusion of autistic children in Jordanian public and private schools.

\section{References}

Abdel Fattah, A. (2018). Teachers' Attitudes towards Integrating Students with Disabilities with their Peers in Salfit Governorate Schools. Published MA thesis. Al-Quds Open University. Palestine

Aljbour, H. (2020). The extent of practicing ethical leadership by public secondary school principals in Amman. Journal of Education and Practice. 11(15). 57-63, DOI: 10.7176/JEP/11-15-07

Al-Smadi, A. (2010). Tendency of teachers to amalgamate handicapped pupils with ordinary pupils in Ar'ar governorate. Islamic University Journal of Humanities Research. 18(2).pp.785-804 .Retrieved from: https://journals.iugaza.edu.ps/index.php/IUGJHR/article/view/863

Al-Suwaiti, A. (2016). Views and opinions of teachers and administrators in the general education towards enrolling of the abnormal children in the ordinary primary school in Al-Kaleel Region. The Journal of the Basic Education College For Educational and Humanities Sciences at Babel University. Issue No. 25, p.114132

American Psychiatric Association. (2013). Diagnostic and statistical manual of mental disorders (5th ed.). Arlington, VA: Author.

Cassady, J. M. (2011). Teachers' attitudes toward the inclusion of students with autism and emotional behavioural disorder, Electronic Journal for Inclusive Education, 2 (7), p. 1-23

Crano, W. D., \& Prislin, R. (2006). Attitudes and persuasion. Annual Review of Psychology, Vol. 57, 345 - 374

Crisman, B.W. (2008). Inclusive Programming for students with autism, Principal, 88(2), 28-32.

Gavalda, J. and Qinyi, T. (2012). Improving the process of inclusive education in children with ASD in mainstream schools. The Proceedings of the 4th World Conference on Educational Sciences (WCES-2012), Spain, 1$4 / / 2 / 2012$

Goodall, C. 2018. The educational experiences of autistic young people: Understand me, support me, include me. Unpublished Thesis. Queen's University. Canada.

Hebron, J., and N. Humphrey (2014). Mental health difficulties among young people on the autistic spectrum in mainstream secondary schools: A comparative study. Journal of Research in Special Educational Needs, 14 (1):22-32.

Huws J.; and Jones R. (2010). They just seem to live their lives in their own little world: Lay perceptions of autism. Disability \& Society. 25(3), pp.331-44.

Kuzminski R, Netto J, Wilson J, Falkmer T, Chamberlain A, Falkmer M (2019) Linking knowledge and attitudes: Determining neurotypical knowledge about and attitudes towards autism. PLoS ONE, 14(7). Retrieved from: https://doi.org/10.1371/journal.pone.0220197

Lindsay, S.; Proulx, M.; Thomson, N.; and Scott, H.. (2013). Educators' challenges of including children with autism spectrum disorder in mainstream classrooms. International Journal of Disability Development and Education. 60(4), pp. 347-362. DOI: 10.1080/1034912X.2013.846470.

Merry, M. (2020). Do Inclusion Policies Deliver Educational Justice for Children with Autism? An Ethical Analysis. Journal of School Choice. 14(1). 9-25, https://doi.org/10.1080/15582159.2019.1644126

Natof, T. H. \& Romanczyk, R. G. (2009). Teaching students with ASD: Does teacher enthusiasm make a difference? Behavioral Interventions, 24(1), pp. 5572.

Osborne, L.A. \& Reed, P. (2011). School factors associated with mainstream progress in secondary education for included pupils with Autism Spectrum Disorders, Research in Autism Spectrum Disorders, 5, 12531263

Roberts, J. and Simpson, K. (2016). A review of research into stakeholder perspectives on inclusion of students with autism in mainstream schools. International Journal of Inclusive Education, 20(10). pp. 1084-1096

Robertson, K., Chamberlain, B., \& Kasari, C. (2003). General education teachers' relationships with included students with autism. Journal of Autism and Developmental Disorders, 33(2), 123-130.

Salehi, M., \& Farhang, A. (2019). On the adequacy of the experimental approach to construct validation: the case of advertising literacy. Heliyon, 5(5). Retrieved from: https://doi.org/10.1016/j.heliyon.2019.e01686

Theeb, R.; and Muhaidat, M. (2013). Skills needed for students with autism to be integrated in regular schools according to teachers' view point. Dirasat: Educational Sciences. 40(4). 1288-1305, http://search.shamaa.org/FullRecord?ID=98079

Thomson, Kate. (2002). Differentiating integration: Special education in the Russian Federation. European Journal of Special Needs Education. 17 (1), p. 33-47. DOI: 10.1080/08856250110099006. 